\title{
PENGARUH KARAKTERISTIK UKM PADA KAPABILITAS INOVASI DAN KINERJA INOVASI UKM (STUDI KASUS PADA SENTRA IKM ALAS KAKI JAWA TIMUR)
}

Esti Dwi Rinawiyanti ${ }^{1}$, Benny Lianto

E-mail: estidwi@staff.ubaya.ac.id ${ }^{1}$

\section{Penulis}

Esti Dwi Rinawiyanti adalah dosen program studi Teknik Industri, Fakultas Teknik, Universitas Surabaya. Menyelesaikan program Magister pada departemen International Management di Fachhochschule Nuertingen University.

Bidang peminatan: Entrepreneurship, Manajemen Industri, Estimasi dan Analisis Biaya.

\section{Abstract}

Footwear industries get the priority in East Java Province because of their big contribution to the economy and labor absorption. In order to survive and to achieve the competitive advantage they need to do innovation. The innovation capabilities can be measured through Technological Innovation Capabilities (TIC), while the innovation performance can be assessed with Technological Innovation Performance (TIP). This research was conducted to identify SMEs characteristics (scale, age, and product type) and to analyze whether there were different impacts of those characteristics on TIC and TIP. Data collection was completed through questionnaire distribution to 192 footwear SMEs in three footwear center in East Java (Surabaya, Sidoarjo, and Mojokerto). The grand mean of each dimension of TIC and TIP was obtained by calculating the results of questionnaire which used Likert scale. The grand mean can be as a description of TIC and TIP level in those three areas. For TIC, the majority footwear SMEs were on the medium and high level. The highest level of TIC was achieved by footwear SMEs in Mojokerto (4.09), Surabaya got a medium (3.18), and Sidoarjo obtained the lowest (2.81). For TIP, the majority of footwear SMEs had the medium and low level. Footwear SMEs in Sidoarjo held the highest level (3.05), then the footwear SMEs in Mojokerto (2.86), and the lowest is footwear SMEs in Surabaya (2.05). Based on the MANOVA analysis it can be recognized that almost all characteristics of footwear SMEs (scale, age, product type) gave no significant impacts on TIC and TIP. Except among footwear SMEs in Surabaya the age of SMEs had an effect on TIC and TIP.

\section{Keywords}

Footwear SMEs, Innovation Capabilities, Innovation Performance

\section{JIEMS}

Journal of Industrial Engineering \& Management Systems Vol. 9, No 2, August 2016 


\section{PENDAHULUAN}

Industri alas kaki bisa menjadi andalan Indonesia di tengah melemahnya perekonomian nasional dan nilai tukar rupiah akhir-akhir ini. Sebab, industri alas kaki merupakan sektor yang nilai perdagangannya terus meningkat dengan ratarata mengalami surplus. Pelaku industri alas kaki nasional saat ini berjumlah 394 perusahaan dengan investasi mencapai Rp 11,3 triliun pada 2014 dan menyerap 643 ribu tenaga kerja karena bersifat padat karya. Bukan hanya dari sisi investasi dan produksi, industri alas kaki juga memberikan devisa yang sangat besar bagi negara. Pada 2014, nilai ekspor produksi alas kaki nasional mencapai USD 4,11 miliar (sekitar Rp 53,4 triliun) atau naik 6,44 persen dari tahun sebelumnya sebesar USD 3,86 miliar. Di samping itu, industri alas kaki merupakan salah satu sektor yang terus meningkat nilai perdagangannya dengan rata-rata nilai surplus dalam lima tahun terakhir mencapai USD 2,84 miliar. Pada akhir 2014, surplus perdagangan produk alas kaki mencapai USD 3,7 miliar (JPNN, 2015). Sementara itu, dalam rangka menghadapi Masyarakat Ekonomi ASEAN (MEA) 2015, alas kaki merupakan satu dari tujuh sektor yang dikembangkan untuk menguasai pasar dalam negeri, selain industri otomotif, elektronika konsumsi, semen, pakaian jadi, furnitur, serta makanan \& minuman (Bappeda, 2014). Di Provinsi Jawa Timur alas kaki yang berada di urutan ketujuh dari sepuluh besar kelompok barang yang diekspor Jatim ke luar negeri mencatatkan nilai ekspor senilai 494 juta dollar AS sepanjang Januari hingga November 2013. (Ayo Gita Bisa, 2014). Alas kaki juga sebagai salah satu industri prioritas yang dikembangkan dengan pendekatan model klaster yang merupakan industri strategis penghasil devisa yang besar dan banyak menyerap tenaga kerja. Pada tahun 2010 industri alas kaki Jawa Timur menyerap tenaga kerja sebanyak 4.000 orang. Jumlah total industri alas kaki sebanyak 3.489 usaha, terdiri dari Industri Penyamakan Kulit (129 usaha), Industri Besar \& Menengah (140 usaha), Industri Kecil (1.380 usaha) dan Sentra IKM (1.840 usaha) (Disperindag, 2011). Dari data tersebut dapat terlihat bahwa mayoritas industri alas kaki di Jawa Timur adalah industri kecil dan industri kecil menengah. Beberapa Sentra IKM tersebar antara lain di Mojokerto 29 IKM, Sidoarjo 518 IKM dan Surabaya 3 IKM (Yulistyati, 2009).

Dengan banyaknya jumlah Sentra IKM alas kaki di Jawa Timur dapat dipastikan bahwa persaingan semakin meningkat tiap tahunnya. Apalagi peningkatan daya saing merupakan salah satu arah kebijakan pengembangan klaster industri alas kaki (Disperindag, 2011). Salah satunya agar IKM dapat berkembang dan memiliki keunggulan daya saing adalah dengan meningkatkan inovasi dan teknologi. Menurut Shan and Jolly (2010) inovasi dapat ditingkatkan melalui peningkatan technological innovation capabilities (TIC) yang terkait secara langsung dengan technological innovation performance (TIP). Oleh karena itu penelitian ini diadakan dengan tujuan untuk mengidentifikasi karakteristik IKM alas kaki dan menganalisa pengaruh karakteristik IKM tersebut pada kapabilitas inovasi (TIC) dan kinerja inovasi (TIP). Pada penelitian ini, obyek penelitian adalah tiga Sentra IKM alas kaki utama di Jawa Timur, yakni Sidoarjo, Surabaya, dan Mojokerto.

Menurut Badan Pusat Statistik (BPS) berdasarkan kuantitas tenaga kerja, usaha kecil merupakan entitas usaha yang memiliki jumlah tenaga kerja 5 sampai 19 orang, sedangkan usaha menengah merupakan entitas usaha yang memiliki tenaga kerja 20 sampai 99 orang. Usaha kecil dan menengah diperhitungkan sebagai salah satu pemicu perekonomian karena kontribusinya pada inovasi teknologi, penyerapan tenaga kerja, dan peningkatan ekspor (Subrahmanya, 2011). Madrid-Guijarro, Garcia dan Auken (2009) menyatakan bahwa inovasi 


\section{JIEMS}

Journal of Industrial Engineering \& Management Systems Vol. 9, No 2, August 2016 secara luas diakui sebagai faktor kunci dalam daya saing bangsa dan perusahaan. Usaha kecil yang tidak merangkul inovasi dalam strategi bisnisnya beresiko menjadi kurang atau tidak kompetitif karena produk dan proses yang sudah usang.

Inovasi teknologi merupakan salah satu faktor kunci pada persaingan usaha. Inovasi teknologi menjadi hal yang tidak terhindarkan bila perusahaan ingin berkembang dan mempertahankan keunggulan daya saingnya serta memasuki pasar yang baru (Becheikh et al. 2006). Technological Innovation Capabilities (TIC) adalah kumpulan karakteristik komprehensif dari suatu perusahaan atau organisasi yang dapat digunakan untuk memfasilitasi dan mendukung strategi inovasi teknologi menurut Burgelman et al. (2004; dalam Yam, C. M, Wiiliam Lo, Esther P. Y, Tang \& Anonio, K. W. Lau, 2010). Terdapat tujuh dimensi yang dapat digunakan untuk menggambarkan TIC menurut Guan \& Ma (2003; dalam Yam, C. M, Guan, J. C, Pun, K. F. and Tam, P. Y, 2004), yakni: learning capability, $R \& D$ capability, resources allocation capability, manufacturing capability, marketing capability, organization capability dan strategic planning capability. Rosli \& Sidek (2013) yang melakukan penelitian pada UKM di Malaysia menyatakan bahwa inovasi, baik inovasi produk dan inovasi proses, mempunyai pengaruh yang signifikan pada kinerja perusahaan. Yam et al (2010) menyebutkan kinerja perusahaan tersebut dengan istilah Technological Innovation Performance (TIP). Terdapat 4 (empat) indikator kinerja yang digunakan dalam mengukur TIP, yakni: kinerja penjualan (sales performance), kinerja inovasi (innovation performance), kinerja produk (product performance), dan pertumbuhan penjualan (sales growth).

Burroine \& Jaiya (2005) mengatakan bahwa kemampuan perusahaan untuk melakukan inovasi bervariasi tergantung pada sektor usaha, ukuran perusahaan, fokus, sumber daya dan lingkungan bisnis di mana perusahaan tersebut beroperasi. Sedangkan Baldwin el al. (1999) dalam penelitiannya menyatakan bahwa perusahaan yang lebih besar lebih inovatif dibandingkan dengan perusahaan yang lebih kecil, karena memiliki kemudahan lebih pada akses pembiayaan, dapat menyebarkan biaya tetap inovasi pada volume penjualan yang lebih besar, manfaat yang diperoleh dari economies of scale, dan saling melengkapinya (complementarities) antara riset dan pengembangan dengan aktivitas-aktivitas yang lain dalam perusahaan. Sedangkan waktu menjadi faktor yang penting untuk dipertimbangkan dalam proses membangun kapabilitas inovasi, merujuk pada lamanya operasional perusahaan mulai berdirinya perusahaan sampai penelitian ini dilakukan dalam besaran tahun. Studi faktorfaktor yang mempengaruhi inovasi pada sektor manufakturing dilakukan pada UKM di Pakistan, khususnya tentang inovasi produk dan inovasi proses (Mahmud \& Ahmed, 2011). Hasilnya menyatakan bahwa faktor internal mempunyai dampak pada inovasi UKM, antara lain meliputi status, ukuran dan kualitas tenaga kerja.

\section{METODOLOGI}

Penelitian ini termasuk dalam applied research, karena penelitian ini bertujuan untuk melakukan identifikasi karakteristik UKM terhadap kapabilitas inovasi dan kinerja UKM. Data yang digunakan pada penelitian ini meliputi data primer dan data sekunder. Data primer diperoleh melalui wawancara, observasi, dan pembagian kuisioner kepada responden, yang sedangkan data sekunder didapatkan melalui data-data yang sudah ada, antara lain dari instansi terkait dan dari internet. Populasi dalam penelitian ini adalah UKM yang terletak pada Sentra IKM alas kaki di tiga kota di Jawa Timur, yakni: Surabaya, Sidoarjo, dan 
Mojokerto. Responden dan pihak yang terlibat dalam penelitian ini adalah para pemilik atau pengambil keputusan dalam suatu UKM. Dalam penelitian ini populasi tidak dapat diambil secara keseluruhan, karena keterbatasan waktu, biaya, dan tenaga yang tersedia. Oleh karena itu diambil sampel yang dianggap dapat mewakili populasi. Teknik pengambilan sampel secara nonprobability sampling dengan metode sampling aksidental atau convenience sampling untuk menentukan UKM alas kaki yang akan dijadikan responden dan menggunakan metode purposive sampling untuk menentukan kriteria responden. Berikut sebaran data sampel di masing-masing Sentra IKM seperti di tabel 1.

Tabel 1. Gambaran besaran sampel penelitian dan sebaran lokasinya

\begin{tabular}{|l|l|l|l|}
\hline No & Sentra IKM & $\begin{array}{l}\text { Jumlah } \\
\text { sampel }\end{array}$ & \multicolumn{1}{|c|}{ Keterangan } \\
\hline 1 & Sidoarjo & $\begin{array}{l}62 \\
\text { UKM }\end{array}$ & Terpusat di daerah Wedoro \\
\hline 2 & Surabaya & $\begin{array}{l}50 \\
\text { UKM }\end{array}$ & $\begin{array}{l}\text { Tersebar di seluruh wilayah Surabaya, terutama di } \\
\text { kecamatan Tambaksari, kecamatan Kenjeran dan } \\
\text { kecamatan Bulak }\end{array}$ \\
\hline 3 & Mojokerto & $\begin{array}{l}80 \\
\text { UKM }\end{array}$ & $\begin{array}{l}\text { Terpusat di kota Mojokerto, yakni di daerah Miji, } \\
\text { Kedungkwali dan pinggiran kota Mojokerto, } \\
\text { yakni: Desa Sinoman, Daleman dan Jampirogo. }\end{array}$ \\
\hline
\end{tabular}

Kuisioner yang dibagikan kepada responden disusun dengan tiga bagian, yaitu:

1. Bagian I berisi 5 pertanyaan untuk mengetahui profil responden dengan jawaban pilihan ganda.

2. Bagian II berisi 44 pernyataan (variabel) untuk mengetahui kemampuan inovasi pada UKM dalam 7 dimensi TIC, meliputi learning capability, $R \& D$ capability, resources allocation capability, manufacturing capability, marketing capability, organization capability, dan strategic planning capability. Tiap dimensi meliputi beberapa variabel dengan rincian seperti di Tabel 2.

3. Bagian III berisi pernyataan untuk mengidentifikasi kinerja inovasi pada UKM dengan 4 dimensi TIP (sales performance, (innovation performance, product performance, dan sales growth) seperti ditampilkan di Tabel 3.

Bagian II dan III ditanyakan dengan skala Likert dan responden menjawab mulai dari skala 1 (Sangat Tidak Setuju) sampai skala 5 (Sangat Setuju). Data yang didapatkan dari penyebaran kuisioner kemudian diolah menggunakan software SPSS 18 dan dianalisa untuk menjawab tujuan penelitian.

\section{JIEMS}

Journal of Industrial Engineering \& Management Systems Vol. 9, No 2, August 2016 
Tabel 2. Variabel generik dari tujuh dimensi TIC

\begin{tabular}{|c|c|c|c|}
\hline Dimensi & Variabel & Dimensi & Variabel \\
\hline \multirow{4}{*}{$\begin{array}{l}\text { Learning } \\
\text { Capability }\end{array}$} & Tingkat pemahaman kerja & \multirow{7}{*}{$\begin{array}{l}\text { Manufacturing } \\
\text { Capability }\end{array}$} & Variasi produk \\
\hline & Tingkat pendidikan pekerja & & Kapasitas produksi \\
\hline & Usia pekerja & & $\begin{array}{l}\text { Ketersediaan alat } \\
\text { produksi }\end{array}$ \\
\hline & Lama bekerja & & $\begin{array}{l}\text { Kelengkapan alat } \\
\text { produksi }\end{array}$ \\
\hline \multirow{14}{*}{$\begin{array}{l}R \& D \\
\text { Capability }\end{array}$} & Jumlah inovasi proses & & $\begin{array}{l}\text { Pengembangan alat } \\
\text { produksi }\end{array}$ \\
\hline & Kondisi fasilitas R\&D & & $\begin{array}{l}\text { Kecanggihan alat } \\
\text { produksi }\end{array}$ \\
\hline & Jumlah inovasi produk & & $\begin{array}{l}\text { Ketrampilan teknis } \\
\text { Pekerja }\end{array}$ \\
\hline & $\begin{array}{l}\text { Variasi desain dan model } \\
\text { produk }\end{array}$ & \multirow{8}{*}{$\begin{array}{l}\text { Marketing } \\
\text { Capability }\end{array}$} & Promosi produk. \\
\hline & Desain produk & & Pola distribusi produk \\
\hline & Jumlah produk baru & & Sumber dan pola order \\
\hline & Keunggulan produk & & Kesesuaian produk \\
\hline & Kelebihan desain & & $\begin{array}{l}\text { Frekuensi promosi } \\
\text { produk }\end{array}$ \\
\hline & $\begin{array}{l}\text { Proses pengembangan } \\
\text { produk }\end{array}$ & & $\begin{array}{l}\text { Program layanan } \\
\text { konsumen }\end{array}$ \\
\hline & Tingkat perubahan produk & & Pengiriman produk \\
\hline & $\begin{array}{l}\text { Keberadaan dan kesadaran } \\
\text { paten }\end{array}$ & & Kesetiaan pelanggan. \\
\hline & $\begin{array}{l}\text { Trend pengembangan } \\
\text { produk }\end{array}$ & \multirow{4}{*}{$\begin{array}{l}\text { Organizational } \\
\text { Capability }\end{array}$} & Kemanpuan koordinasi \\
\hline & $\begin{array}{l}\text { Dampak pengembangan } \\
\text { produk }\end{array}$ & & Kerjasama tim kerja \\
\hline & $\begin{array}{l}\text { Biaya pengembangan } \\
\text { produk }\end{array}$ & & $\begin{array}{l}\text { kerjasama dengan pihak } \\
\text { lain }\end{array}$ \\
\hline \multirow{6}{*}{$\begin{array}{l}\text { Resource } \\
\text { Capability }\end{array}$} & Sumber ide desain produk & & $\begin{array}{l}\text { Pembagian kerja yang } \\
\text { jelas }\end{array}$ \\
\hline & Lokasi strategis perusahaan & \multirow{5}{*}{$\begin{array}{l}\text { Strategy } \\
\text { Capability }\end{array}$} & Visi, misi, target \\
\hline & Jaringan agen penjualan & & \multirow{2}{*}{ Keberadaan strategi } \\
\hline & Jaringan pasar & & \\
\hline & Jaringan supplier & & \multirow{2}{*}{ Sistem evaluasi kinerja } \\
\hline & Jumlah tenaga kerja & & \\
\hline
\end{tabular}

\section{JIEMS}

Journal of Industrial Engineering \& Management Systems Vol. 9, No 2, August 2016
Tabel 3.Variabel dari dimensi TIP

\begin{tabular}{|c|c|c|c|}
\hline Dimensi & Variabel & Dimensi & Variabel \\
\hline \multirow{5}{*}{$\begin{array}{l}\text { Product } \\
\text { performa } \\
\text { nce }\end{array}$} & Kualitas produk & \multirow{4}{*}{$\begin{array}{l}\text { Innovation } \\
\text { Performance }\end{array}$} & \multirow{2}{*}{$\begin{array}{l}\text { Komersilisasi produk } \\
\text { baru }\end{array}$} \\
\hline & Keunggulan biaya & & \\
\hline & Daya saing produk & & \multirow[t]{2}{*}{ Jumlah produk baru } \\
\hline & $\begin{array}{l}\text { Keunikan dan/atau desain } \\
\text { produk }\end{array}$ & & \\
\hline & $\begin{array}{l}\text { Rata-rata waktu peluncuran } \\
\text { produk baru }\end{array}$ & \multirow{3}{*}{ Sales growth } & $\begin{array}{l}\text { Pertumbuhan } \\
\text { penjualan }\end{array}$ \\
\hline \multirow{2}{*}{$\begin{array}{l}\text { Sales } \\
\text { Performa } \\
\text { nce }\end{array}$} & Omset penjualan & & $\begin{array}{l}\text { Pertambahan } \\
\text { order baru }\end{array}$ \\
\hline & Pangsa pasar & & $\begin{array}{l}\text { perluasan } \\
\text { pemasaran baru }\end{array}$ \\
\hline
\end{tabular}




\section{HASIL DAN PEMBAHASAN}

Uji validitas pada tahap sampling ditentukan melalui nilai Corrected ItemTotal Correlation yang acuan nilainya diperoleh dari tabel-r berdasarkan degree of freedom (df) yaitu jumlah sample dikurangi dengan dua, $\mathrm{df}=(\mathrm{N}-2)$ dan hasil uji validitas tersebut dapat dikatakan valid apabila $R_{\text {hitung }}>R_{\text {tabel. }}$. Sedangkan untuk uji reliabilitas ditentukan oleh nilai Croncbach's Alpha dan dikatakan reliabel apabila Croncbach's Alpha $>0,5$. Dari hasil uji validitas dan reliabilitas yang telah dilakukan didapatkan hasil bahwa secara keseluruhan data pertanyaan kuisioner yang diajukan pada saat sampling telah dinyatakan valid dan reliabel, sehingga dengan kata lain penelitian dapat dilanjutkan ke tahap selanjutnya yaitu analisa dan pembahasan.

\section{Analisis Deskriptif}

Melalui analisis ini akan dijelaskan profil umum dan karakteritisk UKM dan diperoleh gambaran tentang kesamaan dan perbedaan karakteristik UKM alas kaki di masing-masing Sentra IKM yang diamati. Berikut rekapitulasi analisis deskripif untuk masing-masing lokasi penelitian pada variabel skala usaha, usia UKM, dan jenis produk yang dihasilkan.

\begin{tabular}{|c|c|c|c|c|}
\hline \multirow[t]{2}{*}{ No } & \multirow[t]{2}{*}{ Variabel } & \multicolumn{3}{|c|}{ Lokasi Penelitian } \\
\hline & & Sidoarjo & Surabaya & Mojokerto \\
\hline 1 & Skala & $\begin{array}{lr}22 \text { UKM } & (36 \%) \\
\text { merupakan } & \text { UKM } \\
\text { skala mikro, } 30 & \text { UKM } \\
(48 \%) \quad \text { merupakan } & \text { UKM skala kecil dan } \\
10 \text { UKM }(16 \%) \\
\text { merupakan UKM } \\
\text { skala menengah. }\end{array}$ & 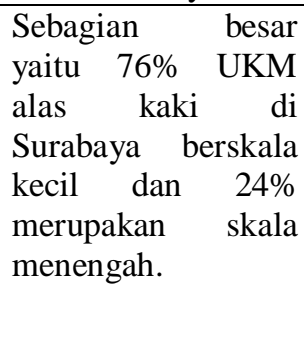 & $\begin{array}{l}35 \text { UKM } \begin{array}{l}\text { skala } \\
(44 \%),\end{array} \\
\text { kecil kemudian sebanyak } \\
17 \text { UKM termasuk } \\
\text { skala usaha mikro } \\
(35 \%) \text {, dan sisanya } \\
28 \text { UKM (35\%) } \\
\text { merupakan usaha } \\
\text { skala menengah. }\end{array}$ \\
\hline 2 & $\begin{array}{l}\text { Usia } \\
\text { UKM }\end{array}$ & 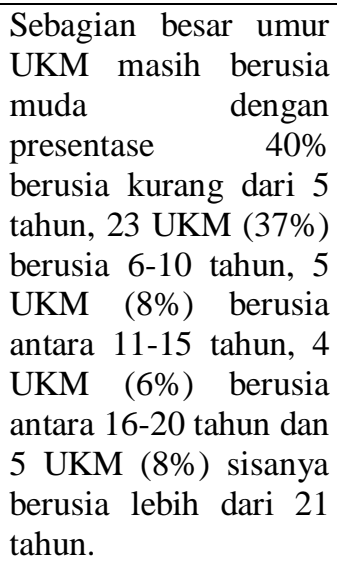 & $\begin{array}{lr}24 \% \text { UKM berusia } \\
11-15 \text { tahun, } 18 \% \\
\text { UKM berusia lebih } \\
\text { dari } 25 \text { tahun, } 16 \% \\
\text { menyatakan } & \text { usia } \\
\text { UKM adalah } 6-10 \\
\text { tahun, } 14 \% \text { UKM } \\
\text { berusia } 16-20 \text { tahun } \\
\text { dan } 21-25 \text { tahun } \\
\text { serta } 12 \% \text { UKM } \\
\text { berusia } 1-5 \text { tahun. }\end{array}$ & $\begin{array}{l}36,25 \% \text { UKM telah } \\
\text { berdiri antara } 6-10 \\
\text { tahun, } 32,5 \% \text { UKM } \\
\text { antara } 11-15 \text { tahun, } \\
16,25 \% \text { UKM } \\
\text { antara } 0-5 \text { tahun } \\
\text { dan sisanya } 15 \% \\
\text { UKM berusia lebih } \\
\text { dari } 16 \text { tahun. }\end{array}$ \\
\hline 3 & $\begin{array}{l}\text { Jenis } \\
\text { Produk }\end{array}$ & $\begin{array}{l}\text { Jenis UKM alas kaki } \\
\text { yang ada di Wedoro } \\
\text { seluruhnya (100\% } \\
\text { UKM) adalah jenis } \\
\text { UKM alas kaki yang } \\
\text { memproduksi sandal. }\end{array}$ & $\begin{array}{l}36 \% \text { UKM produksi } \\
\text { utamanya adalah } \\
\text { sepatu-sandal, } 34 \% \\
\text { sepatu dan } 30 \% \\
\text { memproduksi } \\
\text { sandal. }\end{array}$ & $\begin{array}{lr}53 & \text { UKM } \\
\text { memproduksi } & \\
\text { sepatu, } 17 \text { UKM } \\
\text { memproduksi } \\
\text { sandal dan sepatu), } \\
\text { dan } 10 \\
\text { memproduksi } \\
\text { sandal saja. }\end{array}$ \\
\hline
\end{tabular}

Berdasarkan data-data perbandingan di atas, dapat dikatakan bahwa, jika ditinjau dari skala UKM, terlihat bahwa Sidoarjo dan Mojokerto memiliki karakteristik 
yang hampir serupa, terutama karena masih ditemukannya beberapa UKM (35\%) yang menjadi responden penelitian yang kondisinya masih sangat sederhana (skala mikro). Hal tersebut senada dengan hasil penelitian Sarma dkk di wilayah Bogor (2014), yaitu mayoritas industri alas kaki tergolong pada industri kecil sebesar 54\%, yang sesuai dengan jumlah pekerja yang dimiliki pelaku usaha, yaitu 5 orang. Sedangkan di kota Surabaya tidak terdapat UKM dengan skala mikro. Jika dikaji dari usia perusahaan, UKM alas kaki di sentra Sidoarjo relatif berusia lebih muda (77\% berusia kurang dari 10 tahun) jika dibandingkan dengan UKM di Mojokerto (52,5\% berusia kurang dari 10 tahun) dan UKM alas kaki di kota Surabaya (hanya $28 \%$ berusia kurang dari 10 tahun). Terlihat dengan jelas bahwa UKM alas kaki di kota Surabaya sebagian besar sudah lama Aada, bahkan terdapat $18 \%$ UKM telah berusia lebih dari 25 tahun. Sedangkan dari jenis produk, semua UKM alas kaki di sentra Sidoarjo memproduksi sandal, sepertiga UKM alas kaki di sentra Surabaya menghasilkan sepatu dan sandal, serta mayoritas UKM alas kaki di sentra Mojokerto membuat sepatu.

\section{Analisis TIC dan TIP}

Analisis tingkat kapabilitas inovasi (TIC) dan kinerja inovasi (TIP) masingmasing UKM dilakukan dengan cara menghitung nilai rata-rata (mean) dari tiap variabel pada masing-masing dimensi TIC dan TIP dan kemudian dihitung grand mean tiap dimensi. Skala pengukuran adalah menggunakan skala likert dengan skala 1 sampai 5. Untuk memudahkan pengelompokan dari masing-masing grand mean pada tiap-tiap dimensi atau konstruk, maka tingkat skala dari grand mean tersebut dikelompokkan pada skala pengukuran dengan rumus perhitungan dibawah berikut dan ditentukan masing-masing interval skala, yaitu 1,00-2,33 (rendah), 2,34-3,67 (sedang), dan 3,68-5,00 (tinggi).

$$
\text { Interval }=\frac{(N-1)}{3}=\frac{(5-1)}{3}=\frac{4}{3}=1,33
$$

Keterangan: $\mathrm{N}=$ Skala Likert (1-5)

Untuk analisa TIC dan TIP dan sebagai perbandingan maka yang ditampilkan adalah hasil perhitungan grand mean tiap dimensi dan bukan mean tiap variabel. Berikut disajikan di Tabel 5 rekapitulasi hasil perhitungan grand mean tiap dimensi TIC di masing-masing Sentra IKM. Berdasarkan hasil rekapitulasi pada tabel tersebut terlihat bahwa kondisi dan tingkat TIC tertinggi berada pada Sentra IKM alas kaki Mojokerto dengan rata-rata grand mean 4,09, sedangkan pada Sentra IKM alas kaki Surabaya termasuk sedang $(3,18)$. Rata-rata grand mean TIC terendah berada pada Sentra IKM alas kaki Sidoarjo dengan rata-rata grand mean masing-masing dimensi hanya mencapai 2,81 (sedang).

\section{JIEMS}

Journal of Industrial Engineering \& Management Systems Vol. 9, No 2, August 2016 
Tabel 5. Rekapitulasi grand mean dan kesimpulan kondisi dimensi TIC

\begin{tabular}{|l|l|c|c|}
\hline \multicolumn{1}{|c|}{ Dimensi TIC } & \multicolumn{1}{c|}{ Sidoarjo } & Surabaya & Mojokerto \\
\hline Learning capability & $(1,30)=$ Rendah & $(2,73)=$ Sedang & $(4,23)=$ Tinggi \\
\hline R\&D capability & $(2,52)=$ Sedang & $(3,96)=$ Tinggi & $(4,21)=$ Tinggi \\
\hline Resource capability & $(3,43)=$ Sedang & $(3,47)=$ Sedang & $(4,11)=$ Tinggi \\
\hline $\begin{array}{l}\text { Manufacturing } \\
\text { capability }\end{array}$ & $(3,36)=$ Sedang & $(3,57)=$ Sedang & $(4,19)=$ Tinggi \\
\hline $\begin{array}{l}\text { Marketing } \\
\text { capability }\end{array}$ & $(3,05)=$ Sedang & $(2,94)=$ Sedang & $(3,90)=$ Tinggi \\
\hline $\begin{array}{l}\text { Organizational } \\
\text { capability }\end{array}$ & $(2,47)=$ Sedang & $(1,77)=$ Rendah & $(3,68)=$ Tinggi \\
\hline Strategy capability & $(3,54)=$ Sedang & $(3,88)=$ Tinggi & $(4,32)=$ Tinggi \\
\hline
\end{tabular}

Kajian tentang kondisi dimensi TIC akan menjadi lebih menarik jika dikaitkan dengan kondisi dimensi TIP di masing-masing Sentra IKM alas kaki. Berikut ini adalah rekapitulasi hasil perhitungan grand mean dimensi TIP seperti di Tabel 6.

Tabel 6. Rekapitulasi grand mean dan kesimpulan kondisi dimensi TIP

\begin{tabular}{|l|l|l|c|}
\hline \multicolumn{1}{|c|}{ Dimensi TIP } & \multicolumn{1}{|c|}{ Sidoarjo } & Surabaya & Mojokerto \\
\hline $\begin{array}{l}\text { Product } \\
\text { performance }\end{array}$ & $(3,02)=$ Sedang & $(3,31)=$ Tinggi & $(3,80)=$ Tinggi \\
\hline Sales Performance & $(3,40)=$ Sedang & $(1,60)=$ Rendah & $(2,81)=$ Sedang \\
\hline $\begin{array}{l}\text { Innovation } \\
\text { Performance }\end{array}$ & $(2,95)=$ Sedang & $(1,69)=$ Rendah & $(2,68)=$ Sedang \\
\hline Sales growth & $(2,85)=$ Sedang & $(1,63)=$ Rendah & $(2,15)=$ Rendah \\
\hline
\end{tabular}

Dapat terlihat bahwa sebagian besar dimensi TIP pada semua Sentra IKM berada pada tingkat yang sedang dan rendah. Jika dihitung rata-rata grand mean dari semua dimensi TIP terlihat justru Sentra IKM alas kaki di Sidoarjo yang memiliki TIP tertinggi yaitu 3,05, disusul Sentra IKM Mojokerto $(2,86)$ dan UKM Surabaya $(2,05)$.

\section{Analisis Manova}

Multiple analysis of variance (MANOVA) digunakan untuk mengetahui apakah ada perbedaan kapabilitas inovasi (TIC) dan kinerja inovasi (TIP) jika dilihat dari karakteristik UKM, yaitu skala UKM, usia UKM dan jenis produk yang diproduksi. Pengolahan data menggunakan tingkat $\alpha=5 \%$ untuk masingmasing Multivariate test. Dasar pemilihan variabel karakteristik UKM di atas karena berdasarkan pengamatan di lapangan dan analisis deskriptif, variabel tersebut menjadi pembeda utama di antara Sentra IKM yang diamati. Lebih lanjut Indiarti \& Langenberg (2004) dalam penelitiannya untuk mengidentifikasi faktorfaktor yang mempengaruhi keberhasilan suatu usaha mengkategorisasikan karakteristik UKM meliputi asal usul perusahaan, lamanya perusahaan tersebut telah beroperasi, ukuran perusahaan, dan sumber pendanaannya.

\section{JIEMS}

Journal of Industrial Engineering \& Management Systems Vol. 9, No 2, August 2016

\section{Multivariate Analysis of Variance (MANOVA) pada Kapabilitas Inovasi (TIC)}

Berikut diuraikan gambaran hipotesa dan analisis hasil Multivariate test pada masing-masing karakteristik UKM terhadap TIC. 


\section{Analisis MANOVA Skala UKM dan TIC}

Hipotesis yang digunakan untuk perbedaan skala UKM terhadap Technological Innovation Capability adalah sebagai berikut:

$\mathrm{H}_{\mathrm{o}}$ : Tidak ada perbedaan antara skala UKM terhadap TIC

$\mathrm{H}_{1}$ : Ada perbedaan antara skala UKM terhadap TIC

Surabaya: diperoleh nilai Wilks' Lambda sebesar 0,115>0,05 yang menunjukkan gagal tolak $\mathrm{H}_{\mathrm{o}}$ atau tidak terdapat perbedaan skala UKM terhadap TIC.

Sidoarjo: diketahui nilai Wilks' Lambda sebesar 0,797 > 0,05 yang berarti gagal tolak $\mathrm{H}_{\mathrm{o}}$ atau tidak terdapat perbedaan usia perusahaan pada TIC. Hal ini dapat dimengerti karena mayoritas UKM alas kaki di Sidoarjo (84\%) yang menjadi responden mempunyai skala usaha mikro kecil.

Mojokerto: didapatkan nilai Wilks' Lambda 0,980 > 0,05 yang artinya gagal tolak $\mathrm{H}_{0}$ atau skala UKM tidak berpengaruh terhadap TIC.

\section{Analisis MANOVA Usia Perusahaan dan TIC}

Hipotesis yang digunakan untuk perbedaan Usia UKM terhadap TIC adalah sebagai berikut:

$\mathrm{H}_{\mathrm{o}}$ : Tidak ada perbedaan usia perusahaan terhadap TIC

$\mathrm{H}_{1}$ : Ada perbedaan usia perusahaan terhadap TIC

Surabaya: diperoleh nilai Wilks' Lambda sebesar $0,027<0,05$ yang menunjukkan tolak $\mathrm{H}_{\mathrm{o}}$ atau terdapat perbedaan usia perusahaan terhadap TIC.

Sidoarjo: didapatkan nilai Wilks' Lambda sebesar 0,660>0,05 yang berarti gagal tolak $\mathrm{H}_{\mathrm{o}}$ atau tidak terdapat perbedaan usia perusahaan pada TIC.

Mojokerto: diketahui nilai Wilks' Lambda 0,736 > 0,05 yang artinya gagal tolak $\mathrm{H}_{0}$ atau usia UKM tidak berpengaruh terhadap TIC.

\section{Analisis MANOVA Jenis Produk dan TIC}

Selanjutnya dilakukan analisis manova pada jenis produk terhadap TIC dengan uji hipotesisnya sebagai berikut:

$\mathrm{H}_{\mathrm{o}}$ : Tidak ada perbedaan jenis produk terhadap TIC

$\mathrm{H}_{1}$ : Ada perbedaan jenis produk terhadap TIC

Surabaya: diketahui nilai Wilks' Lambda sebesar 0,236 > 0,05 yang berarti gagal tolak yang $\mathrm{H}_{\mathrm{o}}$ atau tidak ada perbedaan pada jenis produk terhadap TIC.

Sidoarjo: tidak didapatkan nilai Wilks' Lambda karena semua UKM alas kaki di Sidoarjo yang menjadi responden merupakan produsen satu jenis produk, yaitu sandal. Sehingga, dapat dikatakan bahwa tidak terdapat perbedaan antara jenis produk dengan TIC atau jenis produk tidak berpengaruh terhadap TIC dan begitu pula sebaliknya .

Mojokerto: diperoleh nilai Wilks' Lambda 0,555 > 0,05 yang artinya gagal tolak $\mathrm{H}_{\mathrm{o}}$ atau jenis produksi UKM tidak ada perbedaan pada TIC.

Hasil rekapitulasi uji manova dari skala UKM, usia UKSMK dan jenis produk terhadap TIC ditampilkan di Tabel 7. Dapat disimpulkan bahwa hampir seluruh variabel karakteristik UKM alas kaki tidak memberi pengaruh secara signifikan terhadap TIC. Kecuali pada UKM alas kaki di Surabaya terlihat bahwa usia UKM memberi pengaruh signifikan terhadap kapabilitas inovasi UKM (TIC). Temuan ini mendukung hasil penelitian yang menyatakan bahwa kemampuan inovasi perusahaan tidak dipengaruhi oleh besar - kecilnya ukuran (skala) perusahaan (Yanuarto, 2012) dan selaras dengan yang dinyatakan oleh Adagoke (2007) bahwa usia UKM tidak berhubungan dengan inovasi baik yang radikal ataupun incremental. Adinoyi (2014) juga menyatakan bahwa usia perusahaan tidak berpengaruh signifikan pada inovasi perusahaan. Walaupun demikian, 
temuan tersebut tidak sesuai dengan hasil penelitian Marques dan Ferreira (2009) yang menemukan bahwa karakteristik perusahaan yang diukur dari skala usaha, umur perusahaan, level pelatihan, aktivitas sektor dan siklus usaha berpengaruh terhadap kapasitas inovasi perusahaan.

Tabel 7. Rekapitulasi hasil analisis manova antara karakteristik UKM dan TIC

\begin{tabular}{|c|c|c|c|c|c|c|c|}
\hline \multirow[t]{3}{*}{ No } & \multirow{3}{*}{$\begin{array}{l}\text { Karakte- } \\
\text { ristik } \\
\text { Perusa- } \\
\text { haan }\end{array}$} & \multicolumn{6}{|c|}{ Lokasi penelitian } \\
\hline & & \multicolumn{2}{|c|}{ Sidoarjo } & \multicolumn{2}{|c|}{ Surabaya } & \multicolumn{2}{|c|}{ Mojokerto } \\
\hline & & $\begin{array}{c}\text { Signifi- } \\
\text { cant value } \\
\text { Wilks, } \\
\text { Lambda }\end{array}$ & $\begin{array}{c}\text { Kesim- } \\
\text { pulan }\end{array}$ & $\begin{array}{c}\text { Signif- } \\
\text { icant value } \\
\text { Wilks' } \\
\text { Lambda }\end{array}$ & $\begin{array}{c}\text { Kesim- } \\
\text { pulan }\end{array}$ & $\begin{array}{c}\text { Signifi- } \\
\text { cant value } \\
\text { Wilks' } \\
\text { Lambda }\end{array}$ & $\begin{array}{c}\text { Kesim- } \\
\text { pulan }\end{array}$ \\
\hline 1 & $\begin{array}{l}\text { Skala } \\
\text { UKM }\end{array}$ & 0,797 & $\begin{array}{c}\text { Terima } \\
\mathrm{H}_{\mathrm{o}}\end{array}$ & 0,115 & $\begin{array}{c}\text { Terima } \\
\mathrm{H}_{\mathrm{o}}\end{array}$ & 0,980 & $\begin{array}{c}\text { Terima } \\
\mathrm{H}_{\mathrm{o}}\end{array}$ \\
\hline 2 & Usia UKM & 0,660 & $\begin{array}{c}\text { Terima } \\
\mathrm{H}_{\mathrm{o}}\end{array}$ & 0,027 & $\begin{array}{c}\text { Tolak } \\
\mathrm{H}_{\mathrm{o}} \\
\end{array}$ & 0,736 & $\begin{array}{c}\text { Terima } \\
\mathrm{H}_{\mathrm{o}}\end{array}$ \\
\hline 3 & $\begin{array}{l}\text { Jenis } \\
\text { produk }\end{array}$ & - & $\begin{array}{c}\text { Terima } \\
\mathrm{H}_{\mathrm{o}}\end{array}$ & 0,236 & $\begin{array}{c}\text { Terima } \\
\mathrm{H}_{\mathrm{o}}\end{array}$ & 0,555 & $\begin{array}{c}\text { Terima } \\
\mathrm{H}_{\mathrm{o}}\end{array}$ \\
\hline
\end{tabular}

Multivariate Analysis of Variance (MANOVA) pada Kinerja Inovasi (TIP) Berikut diuraikan gambaran hipotesa dan analisis hasil MANOVA pada masingmasing karakteristik UKM terhadap TIP.

\section{Analisis MANOVA Skala UKM dan TIP}

Hipotesis yang digunakan untuk perbedaan Skala UKM terhadap performansi UKM (TIP) adalah sebagai berikut:

$\mathrm{H}_{\mathrm{o}}$ : Tidak ada perbedaan skala UKM pada TIP

$\mathrm{H}_{1}$ : Ada perbedaan skala UKM pada TIP

Surabaya: diperoleh nilai Wilks' Lambda 0,058>0,05 yang menunjukkan gagal tolak $\mathrm{H}_{\mathrm{o}}$ atau tidak ada perbedaan skala UKM pada TIP dan sebaliknya.

Sidoarjo: diketahui nilai Wilks' Lambda 0,765 > 0,05 yang artinya gagal tolak $\mathrm{H}_{\mathrm{o}}$ atau tidak terdapat perbedaan technological Iinovation performance terhadap skala UKM mikro, kecil maupun menengah dan sebaliknya.

Mojokerto: didapatkan nilai Wilks' Lambda 0,056 > 0,05 yang berarti gagal tolak $\mathrm{H}_{0}$ atau skala UKM tidak berpengaruh terhadap TIP.

\section{Analisis MANOVA Usia UKM dan TIP}

Sedangkan untuk perbedaan usia UKM dan TIP menggunakan hipotesis sebagai berikut:

$\mathrm{H}_{\mathrm{o}}$ : Tidak ada perbedaan usia UKM pada TIP

$\mathrm{H}_{1}$ : Ada perbedaan usia UKM pada TIP

Surabaya: diketahui nilai Wilks' Lambda $0,010<0,05$ yang menunjukkan tolak $\mathrm{H}_{\mathrm{o}}$ atau terdapat perbedaan pada usia perusahaan terhadap TIP.

Sidoarjo: didapatkan nilai Wilks' Lambda 0,324 > 0,05 yang berarti gagal tolak $\mathrm{H}_{\mathrm{o}}$ atau tidak terdapat perbedaan TIP terhadap usia UKM.

Mojokerto: diperoleh nilai Wilks' Lambda 0,839 > 0,05 yang artinya gagal tolak $\mathrm{H}_{0}$ atau usia UKM tidak berpengaruh terhadap TIP.

\section{Analisis MANOVA Jenis Produk dan TIP}

Selanjutnya dilakukan analisis manova pada jenis produk terhadap TIP dengan uji hipotesis sebagai berikut:

$\mathrm{H}_{\mathrm{o}}$ : Tidak ada perbedaan jenis produk terhadap TIP

$\mathrm{H}_{1}$ : Ada perbedaan jenis produk terhadap TIP 
Surabaya: didapatkan nilai Wilks' Lambda 0,430>0,05 yang menunjukkan gagal tolak $\mathrm{H}_{\mathrm{o}}$ atau tidak terdapat perbedaan pada jenis produk yang paling banyak diproduksi terhadap TIP.

Sidoarjo: tidak didapatkan nilai Wilks' Lambda karena semua UKM alas kaki di Sidoarjo yang menjadi responden merupakan produsen satu jenis produk, yaitu sandal. Dengan demikian dapat dikatakan bahwa tidak ada perbedaan antara jenis produksi pada $T I P$.

Mojokerto: diketahui nilai Wilks' Lambda 0,447 > 0,05 yang berarti gagal tolak $\mathrm{H}_{\mathrm{o}}$ atau jenis produksi tidak ada perbedaan pada $T I P$.

Berikut disajikan rekapitulasi hasil analisis manova antara karakteristik UKM dan TIP di Tabel 6.

Tabel 6. Rekapitulasi hasil analisis manova antara karakteristik UKM dan TIP

\begin{tabular}{|c|c|c|c|c|c|c|c|}
\hline \multirow[t]{3}{*}{ No } & \multirow{3}{*}{$\begin{array}{c}\text { Karakte- } \\
\text { ristik } \\
\text { Perusa- } \\
\text { haan }\end{array}$} & \multicolumn{6}{|c|}{ Lokasi penelitian } \\
\hline & & \multicolumn{2}{|c|}{ Sidoarjo } & \multicolumn{2}{|c|}{ Surabaya } & \multicolumn{2}{|c|}{ Mojokerto } \\
\hline & & $\begin{array}{c}\text { Signifi- } \\
\text { cant value } \\
\text { Wilks' } \\
\text { Lambda }\end{array}$ & $\begin{array}{c}\text { Kesim- } \\
\text { pulan }\end{array}$ & $\begin{array}{c}\text { Signifi- } \\
\text { cant value } \\
\text { Wilks' } \\
\text { Lambda }\end{array}$ & $\begin{array}{c}\text { Kesim- } \\
\text { pulan }\end{array}$ & $\begin{array}{c}\text { Signifi- } \\
\text { cant value } \\
\text { Wilks' } \\
\text { Lambda }\end{array}$ & $\begin{array}{c}\text { Kesim- } \\
\text { pulan }\end{array}$ \\
\hline 1 & $\begin{array}{l}\text { Skala } \\
\text { UKM }\end{array}$ & 0,788 & $\begin{array}{c}\text { Terima } \\
\mathrm{H}_{\mathrm{o}}\end{array}$ & 0,058 & $\begin{array}{c}\text { Terima } \\
\mathrm{H}_{\mathrm{o}}\end{array}$ & 0,560 & $\begin{array}{c}\text { Terima } \\
\mathrm{H}_{\mathrm{o}}\end{array}$ \\
\hline 2 & Usia UKM & 0,324 & $\begin{array}{c}\text { Terima } \\
\mathrm{H}_{\mathrm{o}}\end{array}$ & 0,010 & $\begin{array}{c}\text { Tolak } \\
\mathrm{H}_{\mathrm{o}}\end{array}$ & 0,430 & $\begin{array}{c}\text { Terima } \\
\mathrm{H}_{\mathrm{o}}\end{array}$ \\
\hline 3 & $\begin{array}{l}\text { Jenis } \\
\text { produk }\end{array}$ & - & $\begin{array}{c}\text { Terima } \\
\mathrm{H}_{\mathrm{o}}\end{array}$ & 0,430 & $\begin{array}{c}\text { Terima } \\
\mathrm{H}_{\mathrm{o}}\end{array}$ & 0,447 & $\begin{array}{c}\text { Terima } \\
\mathrm{H}_{\mathrm{o}}\end{array}$ \\
\hline
\end{tabular}

Dapat disimpulkan dari hasil analisis Manova di atas, bahwa hampir seluruh variabel karakteristik Sentra IKM alas kaki di Jawa Timur tidak memberi pengaruh secara signifikan terhadap TIP. Kecuali pada IKM alas kaki di Surabaya terlihat bahwa usia UKM memberi pengaruh signifikan terhadap kinerja inovasi UKM (TIP). Temuan ini selaras dengan yang dikatakan oleh Niresh \& Velnampy (2014) bahwa usia perusahaan tidak berpengaruh signifikan pada kinerja perusahaan yang diukur melalui profitabilitas. Meskipun demikian, temuan tersebut tidak sesuai dengan hasil penelitian yang menyatakan bahwa skala dan usia perusahaan berpengaruh positif terhadap kinerja perusahaan yang diukur dengan variabel profit (Ilaboya \& Ohiokha., 2016). Coad et al. (2010) juga mengatakan bahwa kinerja perusahaan akan meningkat dengan semakin lamanya perusahaan beroperasi, karena perusahaan yang sudah lama mempunyai tingkat produktivitas yang stabil, keuntungan yang lebih banyak, dan rasio hutang yang lebih rendah.

Berdasarkan hasil analisis manova yang telah dilakukan, dapat diringkas seperti pada tabel 7.

\section{JIEMS}

Journal of Industrial Engineering \& Management Systems Vol. 9, No 2, August 2016 
Tabel 7. Rekapitulasi Hasil MANOVA keseluruhan

\begin{tabular}{|c|c|l|l|l|}
\hline $\begin{array}{c}\text { Karakteristik } \\
\text { UKM }\end{array}$ & Dimensi & \multicolumn{1}{|c|}{ Surabaya } & \multicolumn{1}{|c|}{ Sidoarjo } & Mojokerto \\
\hline \multirow{4}{*}{ Usia UKM } & TIC & Ada perbedaan & $\begin{array}{l}\text { Tidak ada } \\
\text { perbedaan }\end{array}$ & $\begin{array}{l}\text { Tidak ada } \\
\text { perbedaan }\end{array}$ \\
\cline { 2 - 5 } Skala UKM & TIP & Ada perbedaan & $\begin{array}{l}\text { Tidak ada } \\
\text { perbedaan }\end{array}$ & $\begin{array}{l}\text { Tidak ada } \\
\text { perbedaan }\end{array}$ \\
\hline & TIC & $\begin{array}{l}\text { Tidak ada } \\
\text { perbedaan }\end{array}$ & $\begin{array}{l}\text { Tidak ada } \\
\text { perbedaan }\end{array}$ & $\begin{array}{l}\text { Tidak ada } \\
\text { perbedaan }\end{array}$ \\
\hline \multirow{5}{*}{ Jenis produk } & Tidak ada & $\begin{array}{l}\text { Tidak ada } \\
\text { perbedaan }\end{array}$ & $\begin{array}{l}\text { Tidak ada } \\
\text { perbedaan }\end{array}$ \\
\cline { 2 - 5 } & TIP & $\begin{array}{l}\text { Tidak ada } \\
\text { perbedaan }\end{array}$ & $\begin{array}{l}\text { Tidak ada } \\
\text { perbedaan } \\
\text { perbedaan }\end{array}$ & $\begin{array}{l}\text { Tidak ada } \\
\text { perbedaan }\end{array}$ \\
\hline
\end{tabular}

Dari Tabel 7 dapat disimpulkan bahwa secara umum tidak ada perbedaan atau tidak ada pengaruh karakteristik UKM terhadap TIC dan TIP UKM alas kaki, kecuali secara khusus pada UKM alas kaki di Surabaya, variabel usia UKM memberi pengaruh kepada TIC dan TIP.

\section{KESIMPULAN}

Beberapa kesimpulan yang diperoleh dari penelitian ini dapat dijelaskan sebagai berikut. Yang pertama, mengenai profil umum dan karakteristik UKM alas kaki di tiga sentra utama Jawa Tmur. Berdasarkan hasil observasi dan analisis deskritif dapat dikatakan relatif berbeda, terutama jika ditinjau dari skala UKM, usia operasi, dan jenis produk yang dihasilkan. Dari hasil analisis TIC dan TIP dengan mengukur grand mean tiap dimensi dapat disimpulkan bahwa kondisi dan tingkat TIC tertinggi berada pada Sentra IKM alas kaki Mojokerto dengan rata-rata grand mean masing-masing dimensi mencapai 4,09, Sentra IKM alas kaki Surabaya memiliki rata-rata grand mean hanya sebesar 3,18 (sedang), dan nilai TIC terendah berada pada Sentra IKM alas kaki Sidoarjo $(2,81)$. Sedangkan kondisi dimensi TIP terlihat bahwa sebagian besar berada pada tingkat yang sedang dan rendah.

Berdasarkan hasil analisis Manova dapat disimpulkan bahwa hampir seluruh variabel karakteristik UKM alas kaki tidak memberi pengaruh secara signifikan terhadap kapabilitas inovasi (TIC) dan kinerja inovasi (TIP) UKM alas kaki. Kecuali pada UKM alas kaki di Surabaya terlihat bahwa usia UKM memberi pengaruh signifikan terhadap kapabilitas inovasi UKM (TIC) dan sekaligus memberi pengaruh signifikan terhadap kinerja inovasi UKM (TIP).

\section{DAFTAR PUSTAKA}

Adegoke, Oke., Gerard, Burke., Andrew, Myers. 2007. "Innovation Types and Performance in Growing UK SMEs". International Journal of Operations \& Production Management, Vol. 27 Iss 7 pp. 735 - 753.

Adinoyi, Y. Moohammad., Yusof, Nor'Aini., Ernawati, M. Kamal. 2014. "Influences of Firm Size, Age and Sector on Innovation Behaviour of Construction Consultancy Services Organizations in Developing Countries" Business Management Dynamics, Vol.4, No.4, Oct 2014, pp.01-09.

Ayo Gita Bisa (2014), Meubel dan Alas Kaki Masih Jadi Tumpuan Ekspor Jatim, http://www.ayogitabisa.com/news/meubel-dan-alas-kaki-masih-jaditumpuan-ekspor-jatim.html, diakses pada tanggal 27 Juli 2015. 
Alex, Coad., Agusti, Segarra-Blasco., Mercedes, Teruel., 2010. Like Milk or Wine: Does Firm Performance Improve with Age? XREAP Working Paper No. 2010-10, http://papers.ssrn.com/sol3/papers.cfm?abstract $\mathrm{id}=1815028$, diakses pada tanggal 4 Agustus 2016.

Bagas, Y. Setiawan 2009. Penguatan klaster Industri Alaskaki, https://bagasyulistyatis.wordpress.com/2009/03/05/penguatan-klasterindustri-alaskaki/, diakses pada tanggal 27 Juli 2015.

Baldwin, John R. 1999. Innovation, Training and Success, Working Paper Series, Micro Economic Analysis, Division Canada No. 137.

Bappeda Propinsi Jatim (2014), Penyusunan RIPIN Tahun 2015-2035 Perlu Dipercepat, http://bappeda.jatimprov.go.id/2014/06/17/penyusunan-ripintahun-2015-2035-perlu-dipercepat/Penyusunan RIPIN Tahun 2015-2035 Perlu Dipercepat, diakses pada tanggal 27 Juli 2015.

Dinas Perindustrian dan Perdagangan Provinsi Jawa Timur (2011), Pelaksanaan Kebijakan Pembangunan Industri Jawa Timur, disampaikan dalam acara Forum Komunikasi Perencanaan Industri, Surabaya, 8 Juli 2011.

Eko, Yanuarto., Rahab., Untung, Kumorohadi. 2012, Peran Kapabilitas Inovasi Terhadap Perbaikan Produk Usaha Kecil Menengah (UKM) Dengan Tekanan Lingkungan dan Ukuran Perusahaan Sebagai Variabel Moderasi (Studi pada UKM di Kabupaten Purbalingga), Performance Vol. 16 No. 2Sept 2012, http://manajemen.unsoed.ac.id/repositorydocoument-todownload, diakses pada tanggal 3 Agustus 2016.

Indiarti, Nurul., dan Maria, Langenberg. 2004. Factors Affecting Business Success among SMEs: Empirical Evidences from Indonesia. Journal of Asia Entrepreneurship and Sustainability, Volume III, Issue 2.

Jawa Pos National Network (JPNN) (2015), Ekspor Alas Kaki Tembus Rp 53,4 Triliun, http://www.jpnn.com/read/2015/05/08/302736/Ekspor-Alas-KakiTembus-Rp-53,4-Triliun, diakses pada tanggal 27 Juli 2015.

J. Aloy Niresh \& T. Velnampy. 2014. Firm Size and Profitability: A Study of Listed Manufacturing Firms in Sri Lanka. International Journal of Business and Management, Vol. 9, No. 4; 2014, 57-64.

Luecke, Richard dan Ralph, Katz. 2003. Managing Creativity and Innovation. Boston, MA: Harvard Business School Press.

Madrid-Guijarro, A., Garcia, D., Van, Auken, H. 2009. Barriers to innovation among Spanish manufacturing SMEs. Journal of Small Business Management, 47(4), 465-488.

Mahreen, Mahmud dan Hamna, Ahmed. 2011, What Determines Innovation in the Manufacturing Sector? Evidence from Pakistan, pide.org.pk/psde/pdf/AGM27/Mahreen\%20Mahmud.pdf, diakses pada tanggal 3 Agustus 2016.

Ma'mun, Sarma., Farida, R. Dewi., Edward, H. Siregar. 2014. Pengembangan Industri Kecil dan Rumah Tangga Alas Kaki dalam Menuju Keberlanjutan Usaha dan Menghadapi China-ASEAN Free Trade Agreement, Manajemen IKM, Februari 2014 (67-75) Vol. 9 No. 1.

Marques, C. S., dan Ferreira, J. 2009. SME Innovative Capacity, Competitive Advantage and Performance in A 'Traditional' In Dustrial Region of Portugal. Journal of Technology Management \& Innovation. 4 (4), 53-68.

JIEMS

Journal of Industrial Engineering \& Management Systems Vol. 9, No 2, August 2016
M H Bala Subrahmanya. 2011. Technologic lore: Does Innovation Facilitate Growth of Firm Size? The Asian Journal of Technology Management Vol. 4 No. 1 (2011) 41-55, diakses pada tanggal 3 Agustus 2016.

M. Mohd Rosli dan Syamsuriana, Sidek. 2013. The Impact of Innovation on the Performance of Small and Medium Manufacturing Enterprises: Evidence 
from Malaysia, Journal of Innovation Management in Small \& Medium Enterprise, http://www.ibimapublishing.com/journals/JIMSME/jimsme.html, Vol. 2013 (2013), pp 1-16.

Nizar, Becheikh., Re'jean, Landry., Nabil, Amara. 2006 Lessons from Innovation Empirical Studies in The Manufacturing Sector: A Systematic Review of the Literature from 1993-2003. Technovation 26 644-664.

Ofuan, J. Ilaboya dan Izien, F. Ohiokha. 2016. Firm Age, Size and Profitability Dynamics: A Test of Learning by Doing and Structural Inertia Hypotheses. Business and Management Research Vol. 5, No. 1; 2016, 29-39.

Shan, Juan dan Jolly, R. D. 2010. Accumulation of Technological Innovation Capabilities and Competitive Performance in Chinese Firm: a Quantitative Study. IAMOT, Cairo, Egypt, pp. 1-21.

Yam, C. M., Guan, J. C., Pun, K. F., Tam, P. Y. 2004. An Audit of Technological Innovation Capabilities in Chinese Firms: Some Empirical Findings in Beijing, China. Research Policy. Vol. 33, No. 8, pp. 1123-1250.

Yam, C. M., Wiiliam, Lo., Esther, P. Y., Tang., Anonio, K. W. Lau. 2010. Technological Innovation Capabilities and Firm Performance, World Academy of Science, Engineering and Technology. pp. 1023-1030.

\section{JIEMS}

Journal of Industrial Engineering \& Management Systems Vol. 9, No 2, August 2016 